\title{
NOVAS TRILHAS NO MODO DE FAZER PESQUISA EM EDUCAÇÃO ESPECIAL
}

\author{
CRUZ, Mara Monteiro ${ }^{1}$
}

O livro organizado por Leila Regina d'Oliveira de Paula Nunes aborda e discute diferentes metodologias de pesquisa, apresentando aspectos práticose exemplos de estudos realizados em Educação Especial, além de consistente fundamentação teórica.

No primeiro capítulo, Débora Nunes conceitua problema científico e descreve estratégias para a definição de um problema de pesquisa.Nos quatro capítulos que se seguem, são abordadas a Pesquisa Experimental (NUNES e WALTER), a História de Vida (GLAT e VARGAS), a Etnografia (PLETSCH e ROCHA) e a Pesquisa-ação (BRAUN).

Leila Nunes e Cátia Walter descrevem sete modalidades de delineamentos de pesquisa intrassujeitos, apoiando-se em exemplos de pesquisas já realizadas na área. Rosana Glat e Katiuscia Antunesapresentam a metodologia de pesquisa História de Vida como um tipo de investigação que privilegia, como fonte primária de dados, a fala espontânea dos sujeitos. Elas ressaltam que a contribuição desta abordagem metodológica é permitir que grupos historicamente silenciados e marginalizados conquistem um espaço para escuta de sua fala ereafirmem sua condição de protagonistas de suas próprias histórias.MarciaPletsch e Maíra Rocha analisam o uso da abordagem etnográfica em estudos sobre os processos de ensino e aprendizagem de pessoas com necessidades educacionais especiais, principalmente as que têm deficiência intelectual ou múltipla. Patrícia Braundiscute aspectos conceituais, aplicabilidade e implicações da pesquisa-ação em investigações na área da Educação Especial. A autora afirma que este referencial teórico-metodológico pode trazer contribuições para a inclusão, ao possibilitar a organização e implementação de ações educativas que contemplem tanto o investigador quanto o(s) investigado(s), no que diz respeito ao processo de reflexão e ação sobre suas concepções e práticas.

Nosexto capítulo,Cylene Medrado, Vivian Gomes e Francisco Nunes Sobrinho descrevem aspectos teórico-metodológicos da Revisão Sistemática da Literatura (RSL), um instrumento que agrupa, sintetiza e integra evidências científicas geradas por resultados de pesquisas empíricas.

O livro é concluído com o capítulo de Eduardo Manzini, que tece considerações sobre procedimentos para a elaboração de roteiros para grupo focal, um procedimento de coleta de informação verbal que pode ser utilizado em diferentes abordagens teórico-metodológicas.

Em tempos em que a pergunta mais recorrente na área da inclusão escolar é "como fazer?" e considerando-se a complexidade dos elementos que podem compor diferentes respostas cabíveis para realidades de sujeitos e contextos educacionais distintos, a pesquisa, sem dúvida, revela-se como o caminho para a construção deste conhecimento tão caro ao sonho da Educação para todos. Neste sentido, a presente obra é altamente recomendada a todo e qualquer educador comprometido com uma educação que realmente contemple as diferenças.

1 Professora Ajunta do Instituto de Aplicação Fernando Rodrigues da Silveira (CAp-UERJ). E-mail: mara.mcz@gmail.com 